\title{
DETERMINAÇÃo DA LÂMINA MÉDIA DE IRRIGAÇÃO EM PIVÔ CENTRAL
}

\author{
D. DOURADO NETO \\ Departamento de Agricultura - ESALQ/USP, C.P. 9, CEP: 13418-900 - Piracicaba,SP \\ Q. de JONG VAN LIER \\ Departamento de Ciência do Solo - ESALQ/USP, C.P. 9, CEP: 13418-900 - Piracicaba,SP \\ J. A. FRIZZONE \\ Departamento de Engenharia Rural - ESALQ/USP, C.P. 9, CEP: 13418-900 - Piracicaba,SP
}

\begin{abstract}
RESUMO: Com o objetivo de melhorar a exatidão do cálculo da lâmina média d'água, por faixa representativa do coletor, apresentou-se uma expressão, considerando a variação linear de lâmina entre dois coletores subseqüentes, para fins de avaliação do sistema de irrigação do tipo pivố central. Concluiu-se que a expressão proposta deve ser utilizada para determinação da lâmina média ponderada por estar conceitualmente mais correta, apesar de na prática os valores calculados pela metodologia proposta serem muito proximos daqueles obtidos pelo cálculo tradicional.
\end{abstract}

Descritores: irrigação, pivố central, lâmina média ponderada

\section{DETERMINATION OF THE AVERAGE IRRIGATTON DEPTH OF CENTER PIVOT IRRIGATION SYSTEMS}

\begin{abstract}
ARSTRACT: With the purpose of improving the accuracy of the average irrigation depth calculation, an expression is presented assuming linear variation of the depth between two following collectors, for the determination of the average depth of center pivot irrigation systems. It is concluded that the proposed expression should be used for the determination of the mean weighed depth for being conceptually more correct, although, in practice the values calculated by the proposed methodology are very close to those obtained with the traditional calculation method. Key Words: irrigation, center pivot, mean weighed depth
\end{abstract}

\section{INTRODUÇÃO}

Em sistemas de irrigação do tipo pivô central, o conhecimento da lâmina de irrigação média aplicada e da uniformidade de distribuição é imprescindível para o manejo econômico do sistema (DUKE et al., 1992). A lâmina de irrigação média na área efetivamente irrigada é estimada através das lâminas coletadas durante o teste do pivô utilizando um fator de ponderação proporcional à área representada pelo coletor. Segundo norma da ABNT (1985), para execução do teste do pivô, os coletores são dispostos com um espaçamento fixo, sendo o primeiro coletor colocado a uma distância do centro do pivô equivalente à metade do espaçamento.
Assume-se que a lâmina coletada é a própria lâmina média da faixa que o coletor representa, o que, a rigor, não é recomendável, pois faz com que a transição entre duas lâminas consideradas em faixas adjacentes seja descontínua, além de resultar numa determinação conceitualmente incorreta da lâmina média de irrigação na faixa.

A determinação da lâmina média é de suma importância devido a sua ampla utilização na avaliação do sistema de irrigação, pois a mesma é utilizada no cálculo do coeficiente de uniformidade de CHRISTIANSEN (1942), uniformidade de distribuição (CRIDDLE et al., 1956), coeficiente de variação, área defícientemente irrigada, eficiência de aplicação e de armazenagem 
(WALKER, 1979), e na determinação da lâmina de irrigação.

Esta nota tem por objetivo apresentar uma expressão para determinar a lâmina média, assumindo variação linear da lâmina entre dois coletores subseqüentes, para fins de avaliação do sistema de irrigação do tipo pivô central.

\section{Determinação da lâmina média: método usual}

A lâmina coletada $(\mathrm{Li}, \mathrm{mm})$ no $\mathrm{i}$-ésimo coletor é calculada utilizando a seguinte expressão:

$$
L_{1}=\frac{40 \mathrm{Vc}_{\mathrm{l}}}{\pi \cdot \phi_{1}^{2}}
$$

onde $V c_{1}$ refere-se ao volume $\left(\mathrm{cm}^{3}\right)$ coletado, $e_{1}$ ao diâmetro $(\mathrm{cm})$ do i-ésimo coletor.

Convencionalmente a lâmina média ( , $\mathrm{mm}$ ) é determinada utilizando a seguinte expressão:

$$
\Lambda=\frac{\sum_{i=1}^{n}(i-0,5) \cdot L_{1}}{\sum_{i=1}^{n}(i-0,5)}
$$

onde $\mathrm{i}$ refere-se ao número de ordem do i-ésimo coletor, e $\mathbf{n}$ ao número de coletores considerados no teste do pivô.

A expressão utilizada para determinação da lâmina média, apresenta limitação na sua hipótese basilar, a qual define que a lâmina coletada pode ser calculada a partir do volume coletado no i-ésimo coletor, de diâmetro reduzido, assumindo que em toda faixa de abrangência, definida pelo espaçamento entre coletores, precipita exatamente essa lâmina.

Uma vez que os diâmetros dos coletores mais usuais oscilam na faixa de 8 a $10 \mathrm{~cm}$ e os valores modais de espaçamento entre coletores oscilam entre 3 a $5 \mathrm{~m}$, tem-se, nesse caso, que o comprimento relativo de coleta varia de 1,6 a $3,3 \%$.

Como em cada coletor a lâmina coletada é variável, devido a diversos fatores (tais como diferença de pressão e do diâmetro dos bocais e distância do solo entre os emissores, topografia, vento, entre outros), assumiu-se, para efeito de determinação da lâmina média, que a variação da lâmina é linear entre os pontos mensurados.

A rigor, o procedimento correto seria conhecer exatamente o perfil de distribuição do emissor utilizado. Porém, o critério da adoção da variação linear, apesar de não ser o ideal, maximiza a exatidão da determinação da lâmina média em relação ao procedimento usual, que inclusive considera transição abrupta da lâmina coletada entre as faixas de abrangência dos coletores.

\section{Determinação da lâmina média: método proposto}

A área irrigada $\left(\mathrm{A}_{1}, \mathrm{~m}^{2}\right)$ que o $\mathrm{i}$-ésimo coletor representa $E$ assim calculada:

$$
A_{1}=\int_{(i-1) d}^{1 d} 2 \cdot \pi \cdot r \cdot d r
$$

Sendo assim, verifica-se que:

$$
A_{1}=2 \cdot \pi \cdot d^{2} \cdot(i-0,5)
$$

(onde $\mathrm{d}$ refere-se ao espaçamento $(\mathrm{m})$ entre coletores.

Assumindo variação linear entre as lâminas coletadas em quaisquer dois coletores subseqüentes, a lâmina em qualquer ponto entre esses coletores pode ser calculada. Tendo, por exemplo, que as lâminas coletadas nos coletores $\mathrm{i}-1$ e i, distanciados do centro do pivô em (i-1,5).d e (i-0,5).d metros respectivamente, valem $L_{i-1}$ e $L_{1}$ respectivamente, a expressão para o cálculo da lâmina [L(r), mm] entre esses coletores é:

$$
\begin{aligned}
\mathrm{L}(\mathrm{r})= & \mathrm{L}_{1}+\frac{\mathrm{L}_{1}-\mathrm{L}_{1}-1}{\mathrm{~d}}[\mathrm{r}-(\mathrm{i}-1,5) \mathrm{d}], \\
& \forall(\mathrm{i}-1,5) \cdot \mathrm{d} \leq \mathrm{r}<(\mathrm{i}-0,5) \cdot \mathrm{d}
\end{aligned}
$$

onde r refere-se à distância (m) do centro do pivô ao ponto considerado.

Analogamente, entre os coletores $\mathrm{Li}$ e $\mathrm{L}_{1+1}$ tem-se que

$$
\begin{aligned}
L(r)= & L_{1}+\frac{L_{l+1}-L_{1}}{d} \cdot[r-(i-0,5) d], \\
& \forall(i-0,5) \cdot d \leq r<(i+0,5) \cdot d
\end{aligned}
$$

O volume aplicado (Vi, l) na i-ésima coroa, delimitada pelos raios (i-1).d e i.d, é expresso por:

$$
V_{1}=\int_{(1-1) d}^{1 d} 2 \cdot \pi \cdot r \cdot L(r) \cdot d r
$$

sendo assim, temos que:

$$
\begin{aligned}
V_{1} & =\int_{(1-1) d}^{(1-0,5) d} 2 \cdot \pi \cdot r \cdot\left\{L_{1}-1+\frac{L_{1}-L_{1}-1}{d} \cdot[r-(i-1,5) \cdot d]\right\} \cdot d r \\
& +\int_{(1-0,5) d}^{1 d} 2 \cdot \pi \cdot r \cdot\left\{L_{1}+\frac{L_{1}+1-L_{i}}{d}[r-(i-0,5) d]\right\} \cdot d r
\end{aligned}
$$

onde se verifica que: 


$$
\mathrm{V}_{1}=\frac{\pi \cdot \mathrm{d}^{2}}{4} \cdot\left[(\mathrm{i}-0,5) \cdot\left(\mathrm{L}_{1-1}+6 \mathrm{~L}_{1}+\mathrm{L}_{1}+1\right)\right]
$$

e a lâmina média na faixa $(, \mathrm{mm})$ pode assim ser calculada:

$$
\begin{gathered}
\lambda=\frac{\sum_{i=1}^{n} V_{1}}{\sum_{i=1}^{n} A_{1}} \\
\lambda=\frac{1}{8} \cdot \frac{\sum_{i=1}^{n}(i-0,5) \cdot\left(L_{1}-1+6 L_{1}+L_{1}+1\right)}{\sum_{i=1}^{n}(i-0,5)}
\end{gathered}
$$

Diferença do valor da lâmina média determinada pelo método usual e pelo método proposto

A diferença $(, \mathrm{mm})$ do valor da lâmina média determinado pelo método usual e pelo método proposto pode assim ser calculada:

$$
\delta=\lambda-\Lambda
$$

assim, tem-se que:

$$
\delta=\frac{\frac{2 . L_{1}+(2 n+1) L_{n}-(16 n-8) L_{n+1}}{16}}{\sum_{i=1}^{n} i-0,5}
$$

onde se verifica que os valores calculados pela metodologia proposta são muito próximos daqueles obtidos pelo cálculo tradicional.

Pode-se ainda verificar que, para que não haja diferença entre os valores calculados pelos dois métodos, considerando desprezível o termo referente à primeira lâmina coletada, a lâmina coletada no $n+1-e ́ s i m o$ coletor, a qual é desconsiderada no cálculo da área efetivamente irrigada $\left(L_{n+1}\right)$, apresenta a seguinte relação com a n-Esima lâmina coletada:

$$
\mathrm{L}_{n+1}=\frac{1}{8} \cdot \frac{2 n+1}{2 n-1} \cdot L_{n}
$$

sendo assim, nesse caso específico, verifica-se que se houver 100 coletores considerados, que os dois métodos determinará o mesmo valor de lâmina média se a lâmina coletada no $n+1$-ésimo coletor for cerca de $13 \%$ da lâmina coletada no último coletor considerado $\left(L_{n+1}=0,13 \cdot L_{n}\right)$.

Por outro lado, quando o espaçamento entre coletores tende a zero, os dois métodos de cálculo se equivalem.

\section{CONCLUSÃo}

A nova expressão de cálculo da lâmina média, para fins de avaliação e de manejo em sistemas de irrigação por aspersão do tipo pivô central, deve ser utilizada por estar conceitualmente mais correta, apesar de, na prática, os valores calculados pela metodologia proposta serem muito próximos daqueles obtidos pelo cálculo tradicional. 0 uso do método tradicional pode apenas ser justificado em casos de indisponibilidade de recursos computacionais suficientes.

\section{REFERÊNCIAS BIBLIOGRÁFICAS}

\section{ASSOCIAÇĀO BRASILEIRA DE NORMAS}

TÉCNICAS. Sistema de irrigação por aspersāo pivô central: caracterização de desempenho: (Projeto 12:02.08-005). São Paulo, 1985.

CHRISTIANSEN, J. Irrigation by sprinkling. University of Califomia Experimental Station. Berkeley, 1942. 124p. (Bulletin, 670).

CRIDDLE, W.D.; DAVIS, S.; PAIR, C.H.; SHUCKELY, D.G. Methods for evaluation irrigation systems. Washington, USDA, 1956.24p. (Agricultural Handbook, 82).

DUKE, H.R.; HEERMANN, D.F.; DAWSON, L.J. Appropriate depths of application for scheduling center pivot irrigations. Transactions of the ASAE. St. Joseph, v.35, n.5, p.1457-1464, 1992.

WALKER, W.R. Explicit sprinkler irrigation uniformity: efficiency model. Journal of Irrigation and Drainage Division, New York, v.104, p.129-136. 1979.

Enviado para publicação em 13.12.1993 Aceito para publicação em 28.02.1994 